\title{
Genetic and Epigenetic Regulation of Aortic Aneurysms
}

\author{
Ha Won Kim ${ }^{1}$ and Brian K. Stansfield ${ }^{1,2}$ \\ ${ }^{1}$ Vascular Biology Center, Augusta University, Augusta, GA, USA \\ ${ }^{2}$ Department of Pediatrics, Medical College of Georgia, Augusta University, Augusta, GA, USA \\ Correspondence should be addressed to Brian K. Stansfield; bstansfield@augusta.edu
}

Received 1 November 2016; Accepted 15 December 2016; Published 2 January 2017

Academic Editor: Xuwei Hou

Copyright ( 2017 H. W. Kim and B. K. Stansfield. This is an open access article distributed under the Creative Commons Attribution License, which permits unrestricted use, distribution, and reproduction in any medium, provided the original work is properly cited.

\begin{abstract}
Aneurysms are characterized by structural deterioration of the vascular wall leading to progressive dilatation and, potentially, rupture of the aorta. While aortic aneurysms often remain clinically silent, the morbidity and mortality associated with aneurysm expansion and rupture are considerable. Over 13,000 deaths annually in the United States are attributable to aortic aneurysm rupture with less than 1 in 3 persons with aortic aneurysm rupture surviving to surgical intervention. Environmental and epidemiologic risk factors including smoking, male gender, hypertension, older age, dyslipidemia, atherosclerosis, and family history are highly associated with abdominal aortic aneurysms, while heritable genetic mutations are commonly associated with aneurysms of the thoracic aorta. Similar to other forms of cardiovascular disease, family history, genetic variation, and heritable mutations modify the risk of aortic aneurysm formation and provide mechanistic insight into the pathogenesis of human aortic aneurysms. This review will examine the relationship between heritable genetic and epigenetic influences on thoracic and abdominal aortic aneurysm formation and rupture.
\end{abstract}

\section{Introduction}

Aortic aneurysm formation is the result of a thinning medial layer and deterioration of the elastic lamina resulting in weakening of the tensile strength of the arterial wall. Aortic aneurysms are commonly identified in the thoracic and infrarenal aorta, with the latter referred to as abdominal aortic aneurysms (AAA). AAA represent the majority of aortic aneurysms and are classically associated with dyslipidemia, male sex, older age, smoking, and hypertension $[1,2]$. The expansion of AAA is not a passive process but more closely mimics chronic inflammatory diseases characterized by hematopoietic cell infiltration and degradation of the extracellular matrix and vascular structures. Close association of inflammatory cells with breaks in the elastic lamina and the presence of reactive oxygen species suggests that AAA is an indolent process that eventually reaches a stress point resulting in aneurysm rupture $[1,3]$.

Thoracic aneurysms, on the other hand, are relatively rare and exhibit a strong heritable pattern. Approximately 20 percent of persons with thoracic aneurysms have a family history of aortic aneurysms. The relationship between thoracic aortic aneurysms and family history is strongest in first-degree relatives with 10-fold increased risk [4]. Syndromes associated with thoracic aortic aneurysms include Marfan syndrome (MFS), Loeys-Dietz syndrome (LDS), Ehlers-Danlos syndrome (EDS), familial thoracic aortic aneurysms and dissections (TAAD), autosomal dominant polycystic kidney disease (ADPKD), bicuspid aortic valve (BAV), and neurofibromatosis type 1 (NF1). Of these, MFS is the most common familial connective tissue disorder associated with thoracic aortic aneurysm, but each of these heritable syndromes shed light on the pathogenesis of aortic aneurysm formation [5]. A comprehensive understanding of heritable gene mutations and epigenetic modifications associated with aortic aneurysms will allow scientists and clinicians to design effective therapies and identify diseasespecific biomarkers for tracking progression and risk for aneurysm rupture.

\section{Syndromes Associated with Aortic Aneurysms}

Marfan syndrome is the result of mutations in the FBN1 gene on chromosome 15, which encodes fibrillin-1, an extracellular 
TABLE 1: Summary of genetic and epigenetic relationships with TAAD and AAA.

\begin{tabular}{|c|c|c|c|}
\hline Mutation & Syndrome & TAAD & AAA \\
\hline FBN1 [5-8] & Marfan & + & \\
\hline TGFBR1 [9], TGFBR2 $[9,10]$ & Loeys-Dietz & + & \\
\hline COL3A1 [11-14] & Ehlers-Danlos & + & $+1-$ \\
\hline TGFBR2, MYH11 [15, 16], ACTA2 [17, 18] LOX [19], MAT2A [20], SMAD3 [21, 22] & Familial TAAD & + & \\
\hline PKD1 [23, 24], PKD2 [24] & ADPKD & + & $+/-$ \\
\hline NF1 [25-27] & NF1 & + & $+/-$ \\
\hline FBLN5 [28-30] & & + & \\
\hline ELN [14] & Williams & & + \\
\hline MMP2 [31], MMP9 [32], MMP12 [33] & & & $+/-$ \\
\hline MMP3 $[34,35]$ & & & + \\
\hline TIMP1 [14] & & & + \\
\hline LDLR1 $[36,37]$ & & & + \\
\hline APOE E3/E3 [38] & & & + \\
\hline PTPN11 [39-41] & Noonan & + & \\
\hline MTHFR C677T [42-44] & & & + \\
\hline ALOX15 $[45,46]$ & & & + \\
\hline CNN2 [47] & & & + \\
\hline SERPINB9 [47] & & & + \\
\hline ADCY10P1 [47] & & & + \\
\hline miR-21 [48], miR-146a [48] & & & + \\
\hline miR-29b $[49,50]$ & & + & + \\
\hline
\end{tabular}

matrix (ECM) protein that forms microfibrils and controls vessel elasticity. Fibrillin-1 plays a vital role in maintaining the vascular architecture via transforming growth factor- (TGF) $\beta$ signaling, a cytokine that controls cell proliferation and differentiation $[51,52]$. The importance of TGF- $\beta$ signaling in maintaining vascular integrity was confirmed by the identification of mutations in the TGF- $\beta$ receptor genes 1 and 2 (TGFBR1 and TGFBR2), which cause Loeys-Dietz syndrome [53]. Similar to Marfan syndrome, mutations in both TGFBR1 and TGFBR2 result in disruption of collagen and elastin fiber biology in the vessel wall and aortic aneurysm formation [9]. Mutations in TGFBR2 have also been linked to familial thoracic aortic aneurysms and dissections (TAAD), a syndrome associated with aneurysms of the ascending aorta and aortic dissections at relatively early stages of dilatation $[54,55]$. TAAD represents a heterogeneous population of inherited disorders with mutations in myosin heavy chain11 (MYH11) and $\alpha$-smooth muscle actin-2 (ACTA2) among several, which are also linked to TAAD [15, 17, 19-21, 56-61].

Autosomal dominant polycystic kidney disease is commonly associated with intracerebral aneurysms but has been linked to thoracic aortic aneurysms and dissection as well [62, 63]. The etiology of this risk increase is thought to be multifactorial, as persons with ADPKD have increased prevalence of hypertension, a risk factor for thoracic aneurysms and $\mathrm{AAA}$, and mutations in the PKD1 and PKD2 genes increase vascular smooth muscle cell (VSMC) apoptosis and induce dissecting aneurysms in mice [23, 63, 64]. While reports suggest that persons with APDPKD have an increased risk of AAA, a large cohort study failed to demonstrate an increased AAA prevalence in ADPKD [24]. Likewise, cardiovascular manifestations of neurofibromatosis type 1 occur in up to $10 \%$ of patients and tend to occur in adolescents and young adults [25]. Mutations in the NF1 tumor suppressor gene increase VSMC proliferation and apoptosis, while mice with inactivating mutations in $N f 1$ develop more frequent and severe aortic aneurysms than mice without the $N f 1$ mutation $[26,27]$.

\section{Candidate Genes Contributing to Aortic Aneurysm}

The emergence of gene sequencing technology has greatly enabled the systematic search for candidate mutations and single nucleotide polymorphisms (SNPs) associated with aortic aneurysm formation. Much of this focus has been on identifying genes associated with AAA as the heritability of thoracic aneurysms is more commonly recognized [65], although mutational analysis of nonsyndromic thoracic aneurysms has gained interest. Recently, genome-wide association studies (GWAS) have identified several candidate SNPs related to nonsyndromic thoracic aneurysms and AAA [10, 66-68]. Table 1 summarizes genomic and epigenomic relationships with thoracic and abdominal aortic aneurysms. Many of these candidate genes require additional verification and must demonstrate functional plausibility in the pathogenesis of aortic aneurysms.

3.1. Extracellular Matrix Proteins. Fibrillin-1, coded by the FBN1 gene, is an extracellular matrix glycoprotein that helps maintain the structural integrity of elastic fibers and other 
connective tissues. Mutations in the FBN1 gene have been identified in $70-93 \%$ of persons who meet the diagnostic criteria for Marfan syndrome with more than 1,000 unique FBN1 mutations observed in this population $[6-8,69]$. GWAS studies of patients with sporadic thoracic aneurysms identified five independent SNPs in the FBN1 coding region on chromosome 15, which may have predictive and diagnostic ability in nonsyndromic thoracic aortic aneurysms [7].

Fibulins (FBLN) are elastin-binding proteins that associate with fibronectin-containing fibers and lamina within the aorta and other large arteries [28]. FBLN5 functions as a bridging peptide to promote the adhesion of vascular endothelial cells. Mutations in the FBLN5 gene result in cutis laxa and are potentially linked to age-related macular degeneration, a disease characterized by degradation of the elastin support structures [70]. Further, Fbln 5 knockout mice exhibit fragmentation of the elastic lamina and downregulation of FBLN5 is associated with aortic dilation in humans, which supports a role for FBLN5 in the pathogenesis of AAA [29, 71]. However, Badger et al. examined peripheral blood samples from 230 persons with AAA and 278 controls for three common SNPs in the FBLN5 gene locus [30]. The frequency of each SNP was similar between cases and controls.

Degradation of collagen, a major component of the extracellular matrix (ECM), contributes to aneurysm formation and rupture due to a loss of tensile strength within the aorta. The COL3A1 gene encodes a type III collagen found in the vascular wall that provides extensibility to the aorta. Mutations in the COL3A1 gene cause Ehlers-Danlos Syndrome type IV [8] and hemizygous deletions have been linked to familial aortic aneurysm rupture [11]. Similar results were identified in COL3A1 haploinsufficient mice [12, 13]. However, SNP analysis of AAA and control patients for the T581C variant of COL3A1 failed to demonstrate a difference in the allele frequency between study populations [14].

Mutations in the ELN gene, encoding elastin (ELN), result in Williams Syndrome, a syndrome characterized by supravalvar aortic stenosis, cutis laxa, and other disorders of connective tissue [72]. Elastin is a highly elastic protein found in the lamina of muscular arteries and accommodates arterial dilation and facilitates recoil. ELN knockout mice develop severe hypertension and die shortly after birth, while ELN heterozygous mice develop muscularized arteries and moderate hypertension [73]. Additionally, decreased elastin expression potentiates VSMC proliferation and increases arterial fragility. Thus, elastin appears to play an important role in maintaining vascular wall integrity under stress. However, a propensity for aortic aneurysm formation has not been demonstrated in ELN mutant mice. SNPs in the $E L N$ gene have been identified in patients with a strong family history of AAA, but cohort studies of nonrelated AAA and control patients have failed to show a difference in SNP frequency [14].

Matrix metalloproteinases (MMP) are zinc-containing peptidases that are biologically active molecules involved in the degradation of ECM proteins and play an important role in cell proliferation, migration, and apoptosis. Matrix metalloproteinase-2 (MMP2) is highly expressed in VSMC and AAA in both mice and humans, but mutational analysis of AAA and control patients has failed to reveal a predictive SNP in the MMP2 gene [31, 74-79]. Similarly, MMP9 and MMP12 appear to participate in the pathogenesis of AAA in mouse models, but no association between MMP9 or MMP12 gene variants and AAA has been identified [32, 33, 77, 80]. MMP3, on the other hand, is highly expressed in human AAA and a common SNP in the promoter region of the MMP3 gene was found to correlate positively with AAA formation and coronary aneurysms in humans $[34,35]$. Tissue inhibitor of metalloproteinases (TIMPs) inhibits MMP activation and plays a pivotal role in determining the influence of the ECM and cell adhesion molecules on VSMC function within the vascular wall. SNP analysis of the TIMP1 gene has yielded conflicting data with one study showing an association with AAA patients without a family history of AAA and a larger meta-analysis failing to show an association between TIMP1 polymorphisms and AAA $[14,81]$. No association between AAA and TIMP2 or TIMP3 has been identified [14].

3.2. TGF- $\beta$ Pathway. Transforming growth factor- $\beta$ (TGF$\beta$ ) is a cytokine that regulates a variety of cellular functions, including differentiation, transformation, and proliferation. Dysregulated TGF- $\beta$ signaling has been implicated in the pathogenesis of both thoracic aneurysms and AAA. The TGF- $\beta$ superfamily members can bind to fibrillin; therefore, fibrillin-1 deficiency impairs matrix sequestration of latent TGF- $\beta$, leading to uncontrolled secretion of TGF- $\beta$ and upregulated TGF- $\beta$ signaling $[82,83]$. More recently, noncanonical TGF- $\beta$ signaling through SMAD proteins has been shown to induce thoracic aortic aneurysm formation via the mitogen-activated protein kinase (MAPK) pathway [84-86]. These later observations are particularly interesting as SMAD mediated MAPK activation overlaps with other syndromes with a predisposition for thoracic aneurysm formation.

Likewise, TGF- $\beta$ signaling has been implicated in the inflammatory AAA animal models and human AAA. However, TGF- $\beta$ appears to play a protective role in AAA. TGF- $\beta$ and TGFBR 2 are poorly expressed in human AAA tissue samples compared to controls and disruption of TGF- $\beta$ signaling prevents AAA formation in the elastase and angiotensin (AngII) animal models of AAA [87-90]. Interestingly, AngII increases the expression and activation of all TGF- $\beta$ isoforms and TGFBR1 and TGFBR2 within both the thoracic and abdominal murine aorta [91-93]. Analysis of the TGFB1 and TGFBR1 genes failed to reveal an association with human AAA $[14,81]$, but two SNPs in TGFBR2 (rs1036095 and rs4522809) were associated with AAA [10]. Additionally, mutations in the SMAD3 gene have been linked with aneurysm-osteoarthritis syndrome, which further demonstrates the critical role of noncanonical TGF- $\beta$ in aortic aneurysm formation [22].

3.3. Smooth Muscle-Related Proteins. Smooth muscle cells, along with the elastic lamina and ECM, provide the structural integrity of the vascular wall. Thus, mutations affecting VSMC function and/or their ability to maintain the ECM could render the aorta vulnerable to dilation and/or rupture. Mutations in smooth muscle myosin (MYH11), coding for 
smooth muscle myosin heavy chain, have been linked to isolated familial thoracic aortic aneurysm [16]. Ascending aortic aneurysms in patients with MYH11 mutations are accompanied by a high rate of patent ductus arteriosus (PDA), but disruption of this locus is responsible for only a small fraction of sporadic PDA $[16,94]$. Similarly, mutations in $\alpha$-smooth muscle actin (ACTA2) are associated with several manifestations of cardiovascular disease including thoracic and cerebral aneurysms, myocardial infarction, and neurovascular malformations [18]. Given that ACTA2 is a component of smooth muscle cells and also a transcriptional target of TGF- $\beta$ signaling, mutations in this gene likely affect VSMC functions and impair vascular contraction.

3.4. Lipid Metabolism. Apolipoprotein E (APOE) binds to the low-density lipoprotein receptor (LDLR) to clear lipoprotein particles from the blood and is critical for lipid and lipoprotein metabolism. Mutations in the $L D L R$ gene are linked to familial hypercholesterolemia and type III hyperlipidemia, which significantly increase the susceptibility to premature and severe atherosclerosis [95]. GWAS have identified mutations in the $L D L R$, located on chromosome 19p13.2, and the low-density lipoprotein receptor-related protein 1 (LRP1), located on chromosome 12q13.3, which are associated with genetic susceptibility to AAA $[36,37,96]$. Additionally, several APOE polymorphisms modify the risk for atherosclerosis and AAA. Multiple studies have examined APOE $* 2,-* 3$, and $* 4$ alleles in patients with AAAs, and individuals with the E3/E4 genotype showed a markedly lower AAA expansion rate than those with the E3/E3 genotype [38]. Interestingly the E4 genotype is associated with shorter lifespan in several cross-sectional epidemiologic studies [97-99].

3.5. RAS-Related Pathway. Neurofibromin is encoded by the NF1 tumor suppressor gene and functions as a negative regulator of $\mathrm{p} 21^{\text {Ras }}$ (Ras) activity in circulating hematopoietic and vascular wall cells [26, 100-103]. Mutations in the NF1 gene are associated with neurofibromatosis type I and Watson syndrome, a variant of NF1 [104]. The incidence of cardiovascular disease and aneurysm formation in persons with NF1 approaches 10\% [105-109]. Most aortic aneurysms in NF1 are located in the thoracic descending aorta, but animal models of $\mathrm{Nfl}$ mutant animals demonstrate a strong predisposition for infra-renal AAA as well [27]. Broader epidemiologic studies of NF1 patients and aneurysm risk have yet to be performed.

PTPN11 (SH2 domain-containing protein tyrosine phosphatase-2) is encoded by the PTPN11 gene and regulates a variety of cell functions, including mitogenic activation and gene transcription. Mutations in the PTPN11 gene cause Noonan syndrome, a relatively rare inherited disorder characterized by accelerated Ras-MAPK signaling transduction. Persons with Noonan syndrome are at increased risk for dilation of the aortic root and aneurysm formation in the ascending aorta [39-41]. It is mechanistically plausible that other inherited mutations in the Ras pathway may modify the risk of thoracic aneurysm formation, but animal studies and/or human data supporting this hypothesis are limited.

\section{Epigenetic Risk Factors}

Epigenetics refers to heritable and acquired modifications to the genome that alter gene expression without changing the DNA sequence. In some instances, epigenetic modifications are stable and passed on to future generations, but many modifications are relatively dynamic and responsive to environmental cues. Epigenetic modifications include DNA methylation, histone modifications, and noncoding RNA, which can directly interact with the primary nucleotide sequence and regulate gene expression. Methyltransferases are enzymes that methylate DNA and the supporting elements including histones to alter gene activity and chromatin structure. DNA methylation occurs naturally as a result of aging and cell differentiation but is also recognized as an important modifier of disease risk.

Similarly, posttranslational histone modification by the addition or removal of methyl or acetyl groups, phosphorylation, ubiquitylation, and sumoylation results in suppression or activation of gene transcription by altering the chromatin structure or recruiting additional histone modifiers. Modifications that increase chromatin condensation restrict access of transcription factors to the gene target, while modifications that decrease chromatin condensation lead to a more open chromatin structure and increase gene expression. Histone modifying enzymes, such as histone deacetylases (HDACs), histone methyltransferases (HMT), and histone acetyltransferases (HAT), have been implicated in cardiovascular disease, cancer initiation and propagation, and Alzheimer's disease. Presently, epigenetic effects on the frequency, severity, and progression of thoracic aneurysms and AAA are limited with most of the data on AAA being inferred from studies of atherosclerosis and other inflammatory conditions. However, atherosclerosis and AAA are distinct clinical entities with overlapping risk factors and disease mechanisms. Thus, interpretation of study results from related cardiovascular diseases must be viewed with some caution.

4.1. Epigenetic Modification in Matrix Degradation. MMP expression and activation are a hallmark feature of AAA. In particular, MMP-2 and MMP-9 are highly expressed in human and murine AAA and likely have some role in thoracic aortic aneurysms [75, 77, 110-112]. Increased expression of active MMPs predicts severity of other chronic inflammatory diseases such as rheumatoid arthritis, chronic kidney disease, and degenerative inflammatory disorder [113115]. Demethylation of the $M M P 2$ gene promoter increases MMP-2 expression in noninvasive breast cancer cell lines and cells treated with trichostatin A, an HDAC inhibitor, demonstrated increased histone acetylation and reduced MMP2 mRNA expression [116, 117]. Likewise, methylation and acetylation of $M M P 9$ result in downregulation of MMP9 expression and inhibit MMP-9 binding to the CREB transcription factor via Class II major histocompatibility complex transactivator, respectively [118, 119]. Interestingly, HDAC2 binding to the MMP9 promoter region suppresses MMP-9 expression and suggests that epigenetic modification of MMPs is tightly regulated [120]. While MMP expression is highly associated with human and murine aortic aneurysms, 
the regulation of MMP expression in cardiovascular tissues or primary cells remains poorly understood.

Classes I and II HDACs contain a conserved HDAC domain but differ in their expression patterns with broad expression of Class I HDACs and more limited expression of Class II HDACs. In human AAA, Galán et al. recently reported increased expression of HDACs 1, 2 (Class I), 4, and 7 (Class II) in human AAA compared to aortic tissue samples from healthy organ donors [121]. Further, the use of HDAC inhibitors significantly reduced AngII-induced AAA in $A P O E$ knockout mice via downregulation of MMP-2 and MMP-9 in the vascular wall [122]. Administration of Class I or Class II HDAC inhibitors were efficacious in reducing the frequency and severity of AAA in mice, which further supports the hypothesis that epigenetic modifications are critical to the pathogenesis of aortic aneurysms and HDAC inhibitors represent a promising therapeutic strategy [121].

Epidemiologic data suggests that carriers of the MTHFR C677T allele are at increased risk for AAA [42-44]. Persons with this polymorphism express a heat-labile MTHFR enzyme with reduced activity and increased plasma homocysteine levels, which is a known risk factor for AAA and growth rate [123-125]. Homocysteine is considered a potent inhibitor of methyltransferases by increasing the intracellular accumulation of s-adenosyl homocysteine and sequestering methyl donor groups [126, 127]. In support of this hypothesis, MTHFR knockout mice exhibit global DNA hypomethylation and enhanced atherosclerosis, although an increased susceptibility to AAA in animal models has not been demonstrated [128]. The role of methyltransferases in AAA is an emerging area of interest.

4.2. Epigenetic Modification in Smoking. Smoking is a strong risk factor for AAA; however, the underlying mechanisms for this risk association are poorly understood. Exposure to prolonged smoking alters the epigenome, particularly in high-turnover cell lines such as bone marrow-derived leukocytes. Current smoking status and prenatal exposure to cigarette smoke strongly influence the methylation signature of DNA [129-132]. In one of the most insightful studies of cigarette exposure and the epigenome, Stephanie London and colleagues conducted a meta-analysis of 15,907 individuals to identify the methylation footprint of smokers and nonsmokers across the epigenome [133]. They showed that $1 / 3(>7,000)$ of currently recognized human genes have smoking-associated methylation patterns. Interestingly, CpGs (cytosine-rich methylation sites) that are causally related to cardiovascular diseases showed the strongest correlations for both current and former smokers as compared to persons who have never smoked [133]. Former smokers appear to have a methylation signature that more closely mimics nonsmokers; however, smoking cessation does not appear to fully reverse these changes [133-135].

Examination of specific gene promoters has identified similar changes in DNA methylation for candidate genes associated with AAA formation including protease-activated receptor-4 (PAR4 or F2RL3) and 15-lipoxygenase (ALOX15). Breitling et al. examined the methylation status of 27,000 CpGs to show that methylation of the F2RL3 gene was reduced by $12 \%$ in smokers when compared with nonsmokers [130]. Further, CpG methylation correlated negatively with the quantity of cigarettes smoked and positively with duration of smoking abstinence. Broader examination of intergenic CpG methylation has identified similar relationships between smoking and altered DNA methylation [136, 137]. Methylation status of the Alox15 promoter directly affects gene expression with heavy smokers showing a substantial increase in 15-lipoxygenase levels compared to nonsmokers [138, 139]. 15-Lipoxygenase has been implicated in the pathogenesis of AAA and pharmacologic or genetic inhibition of 5lipoxygenase signaling has demonstrated efficacy in preventing AAA in animal models $[45,46]$. However, further epigenomic studies of human AAA are needed to demonstrate the precise mechanisms relating smoking to AAA formation.

4.3. Epigenetic Modification in Aging. Older age is associated with higher risk for AAA and aging-related epigenetic changes have been proposed as a potential mechanism for this increased risk. After methylation patterns have been established during human development, progressive, timedependent, global hypomethylation occurs [140-142]. Most of these observations have been made in primary cell lines or animal models of cancer and other age-related diseases with few observations in older adults with AAA. Studies of atheroma in humans and atherogenic mice exhibit a global loss of genomic 5-methyl-Cytosine content, a common occurrence in neoplastic cells [143-145]. 5-Methyl$\mathrm{C}$ is produced by transfer of a methyl group from Sadenosylmethionine, a process that is inhibited by decreased MTHFR activity and elevated homocysteine levels associated with aging [146-148]. One investigator proposes that DNA methylation measures the cumulative effect of the epigenetic maintenance system and may predict many age-related diseases [149]. These observations are likely relevant to aging and increased risk for AA formation.

4.4. Epigenetic Modification in Inflammatory Responses. Chronic inflammation characterizes AAA, wherein inflammatory leukocytes and cytokines as well as reactive oxygen species are found within the vascular wall in human AAA and animal models of AAA. Inflammation also influences the epigenome of circulating leukocytes and vascular wall cells. Ryer et al. examined the genome-wide DNA methylation profiles of mononuclear cells isolated from 20 humans with AAA and 21 controls. Four genes with differential CpG methylation were identified: kelch-like family member 35 (KLHL35), calponin 2 (CNN2), serpin peptidase inhibitor clade B (ovalbumin) member 9 (SERPINB9), and adenylate cyclase 10 pseudogene 1 (ADCY10P1) [47]. For three of these genes (CNN2, SERPINB9, and ADCY1OP1), methylation more closely correlated with the presence of AAA than with either age or smoking status and suggests that the methylation status of these genes may represent an independent and additive risk factor for AAA.

Changes in DNA methylation within the promoter region of immunomodulatory cytokines may also affect risk for AAA. Treatment of cultured human lymphocytes with interleukin-6 increases global methylation in these cells [114]. 
Promoter methylation regulates the expression and activity of other inflammatory cytokines implicated in AAA formation including TNF- $\alpha$, IL- $1 \beta$, and monocyte chemotactic protein1 (MCP-1 or CCL2) [150-154]. Likewise, reactive oxygen species (ROS) can increase histone acetylation via modulation of HAT activity to promote inflammation in several cell lines [155-157]. Hydrogen peroxide induces gene acetylation by increasing HAT activity and suppressing HDAC activity [158]. Thus, blunting oxidative stress may be a promising strategy to suppress inflammatory conditions such as AAA.

4.5. Noncoding RNAs in AAA. Noncoding RNAs (ncRNA) are functional RNA transcribed from DNA but fail to be translated into proteins. ncRNA, including transfer RNA (tRNA), ribosomal RNA (rRNA), microRNA (miRNA), and long noncoding RNA (lncRNA), are abundant, biologically active molecules that modify gene expression. MicroRNA are short (21-25 nucleotides), single-stranded RNA molecules that mimic small interfering RNA and function in RNA silencing and posttranscriptional regulation of gene expression.

A significant number of miRNAs are differentially expressed in AAA and normal aortic tissue samples; however, most studies fail to identify similar miRNA trends, which is likely due to the heterogeneity of AAA tissue [159]. Pahl et al. showed that AAA have increased expression of miR-181a, $-146 a$, and -21 and lower expression of miR-133b, -331-3p, 133a, -30c, and -204 when compared with control biopsies [160]. Other miRNA with differential expression in AAA and control tissue include miR-126, -20a, -27a, -155 -221, $222,-223,-124 a,-29 b$, and let-7 [161]. Of these, miR-21 and -146a expressions are consistently elevated in AAA compared to healthy aorta, and miR-21 has been shown to inhibit VSMC apoptosis and protect against AAA formation in APOE knockout mice [48]. Several other miRNA, including miR-146a, promote VSMC survival and participate in the pathogenesis of AAA $[49,162,163]$. Interestingly, miR-29b has been implicated in both AAA and thoracic aneurysms associated with Marfan syndrome $[49,50]$.

Analysis of circulating miRNAs in peripheral blood has also yielded useful insight into AAA. Zhang et al. identified increased expression of miR-191-3p, -455-3p, and -1281 in the whole blood of AAA patients compared to controls, while a separate study showed decreased expression of miR-126, 124a, -146a, -155, -223, -29b, -15a, and -15b in AAA [164, 165]. Stather et al. reported reduced expression of let-7e, miR$15 \mathrm{a}$, and $-196 \mathrm{~b}$ in the peripheral blood of AAA patients and increased expression of miR-411 as compared to controls [165]. The increased expression of some miRNA in AAA tissue and decreased expression in peripheral blood (i.e., miR-146a and miR-29b) demonstrate the complex nature of using miRNA as biomarkers of disease progression. Larger studies comparing miRNA expression in peripheral blood and primary tissue would shed considerable light on the role of miRNA in AAA formation.

Recently, an intense interest in the role of noncoding RNAs has broadened our understanding of the influence of the epigenome on aortic aneurysm formation. After showing that miR-29b is significantly downregulated in two animal models of AAA, Maegdefessel et al. showed that administration of an anti-miR to further diminish miR-29b expression in the aortic wall reduced aorta dilation and AAA formation [49]. Conversely, administration of a pre-miR-29b to increase miR-29b expression within the aorta exacerbated AAA formation and aneurysm rupture (63\% versus 33\%). In both animal models and human AAA tissue samples, miR$29 \mathrm{~b}$ appears to target genes that encode extracellular matrix proteins including Collal, Col3al, Col5al, and ELN as well as matrix metalloproteinases (i.e., MMP9). This same group identified a role for miR-29b in thoracic aortic aneurysms in a murine model of Marfan syndrome. Contrary to AAA, aortas from Fbn1 mutant mice (Marfan) expressed higher quantities of miR-29b, which corresponded with enhanced apoptosis, increased MMP expression, and suppression of nuclear factor kappa-light-chain-enhancer of activated B cells (NF- $\kappa \mathrm{B})$ activity, a repressor of miR-29b [50]. Boon et al. examined the aortas of young and old mice as well as tissue samples of human thoracic aneurysms to identify patterns of microRNA expression. The miR-29 family was highly expressed in aortas from older mice and was associated with downregulation of ECM protein expression [166]. Similar to the mice, human tissue samples of thoracic aortic aneurysm expressed high levels of miR-29b when compared to human controls.

While the data for a pathological role for miR-29b in AAA is compelling, other miRNAs have been implicated in AAA as well. miR-21 controls VSMC proliferation and apoptosis during AAA formation and upregulation of miR-21 has been demonstrated in AAA biopsy samples [48]. Nicotine enhances both miR-21 expression and AAA size in mice and AAA biopsy samples isolated from frequent smokers showed a twofold increase in miR-21 expression when compared with AAA from nonsmokers [48]. In both mice and humans, the increase in miR-21 expression was associated with reduced expression of phosphatase and tensin homolog (PTEN) and increased activation of protein kinase B (Akt).

Murine AAA exhibited increased expression of miR-24 with genetic deletion of miR-24 further enhancing murine AAA size and severity [167]. Chitinase 3-like 1 gene (Chi311), which promotes cytokine synthesis in leukocytes and VSMC migration, appears to be a potential target of miR-24 [167]. Additionally, miR-712 and its human homolog miR-205 suppress metalloprotease inhibitor activity in response to AngII to stimulate MMP activity in aortic VSMC and facilitate AAA formation [168]. Although miRNA influence aortic aneurysm formation and severity, it remains to be seen if targeting specific miRNA is a viable therapeutic approach for the prevention or treatment of human aortic aneurysms.

\section{Conclusions}

In this review, we provide a comprehensive assessment of the genetic and epigenetic landscape of aortic aneurysms. We have long appreciated the influence of inherited syndromes on aortic aneurysm formation and aneurysm rupture and the multiple environmental and familial risk factors associated with AAA, but more and more, we are gaining insight into the complexities of gene regulation and protein function in the pathogenesis of aortic aneurysms. Of these recent advances, 
miRNAs and epigenetic modifiers are particularly intriguing and may represent viable therapeutic targets for patients with aortic aneurysms as seen in other patient populations. Future work must include comparisons between findings in human tissue and animal models of aortic aneurysm to draw clinically relevant conclusions about the role of miRNAs or other epigenome modifiers in aortic aneurysm formation.

\section{Competing Interests}

The authors declare that no conflict of interests exists regarding the publication of this paper.

\section{References}

[1] N. L. Weintraub, "Understanding abdominal aortic aneurysm," The New England Journal of Medicine, vol. 361, no. 11, pp. 11141116, 2009.

[2] J. A. Cowan Jr., J. B. Dimick, P. K. Henke, J. Rectenwald, J. C. Stanley, and G. R. Upchurch Jr., "Epidemiology of aortic aneurysm repair in the United States from 1993 to 2003," Annals of the New York Academy of Sciences, vol. 1085, pp. 1-10, 2006.

[3] A. Wanhainen, K. Mani, and J. Golledge, "Surrogate markers of abdominal aortic aneurysm progression," Arteriosclerosis, Thrombosis, and Vascular Biology, vol. 36, no. 2, pp. 236-244, 2016.

[4] G. Albornoz, M. A. Coady, M. Roberts et al., "Familial thoracic aortic aneurysms and dissections-incidence, modes of inheritance, and phenotypic patterns," Annals of Thoracic Surgery, vol. 82, no. 4, pp. 1400-1405, 2006.

[5] H. C. Dietz, C. R. Cutting, R. E. Pyeritz et al., "Marfan syndrome caused by a recurrent de novo missense mutation in the fibrillin gene," Nature, vol. 352, no. 6333, pp. 337-339, 1991.

[6] L. Faivre, A. Masurel-Paulet, G. Collod-Beroud et al., "Clinical and molecular study of 320 children with marfan syndrome and related type I fibrillinopathies in a series of 1009 probands with pathogenic FBN1 mutations," Pediatrics, vol. 123, no. 1, pp. 391398, 2009.

[7] S. A. LeMaire, M.-L. N. McDonald, D.-C. Guo et al., "Genomewide association study identifies a susceptibility locus for thoracic aortic aneurysms and aortic dissections spanning FBN1 at 15q21.1," Nature Genetics, vol. 43, no. 10, pp. 996-1000, 2011.

[8] G. Collod-Béroud, S. Le Bourdelles, L. Ades et al., "Update of the UMD-FBN1 mutation database and creation of an FBN1 polymorphism database," Human Mutation, vol. 22, no. 3, pp. 199-208, 2003.

[9] B. L. Loeys, J. Chen, E. R. Neptune et al., "A syndrome of altered cardiovascular, craniofacial, neurocognitive and skeletal development caused by mutations in TGFBR1 or TGFBR2," Nature Genetics, vol. 37, no. 3, pp. 275-281, 2005.

[10] A. F. Baas, J. Medic, R. van 't Slot et al., "Association of the TGF$\beta$ receptor genes with abdominal aortic aneurysm," European Journal of Human Genetics, vol. 18, no. 2, pp. 240-244, 2010.

[11] S. Kontusaari, G. Tromp, H. Kuivaniemi, R. L. Ladda, and D. J. Prockop, "Inheritance of an RNA splicing mutation (G+ 1 IVS20) in the type III procollagen gene (COL3A1) in a family having aortic aneurysms and easy bruisability: phenotypic overlap between familial arterial aneurysms and Ehlers-Danlos syndrome type IV," American Journal of Human Genetics, vol. 47, no. 1, pp. 112-120, 1990.
[12] L. B. Smith, P. W. F. Hadoke, E. Dyer et al., "Haploinsufficiency of the murine Col3al locus causes aortic dissection: a novel model of the vascular type of EhlersDanlos syndrome," Cardiovascular Research, vol. 90, no. 1, pp. 182-190, 2011.

[13] J. Faugeroux, H. Nematalla, W. Li et al., "Angiotensin II promotes thoracic aortic dissections and ruptures in Col3al haploinsufficient mice," Hypertension, vol. 62, no. 1, pp. 203208, 2013.

[14] T. Ogata, H. Shibamura, G. Tromp et al., "Genetic analysis of polymorphisms in biologically relevant candidate genes in patients with abdominal aortic aneurysms," Journal of Vascular Surgery, vol. 41, no. 6, pp. 1036-1042, 2005.

[15] H. Pannu, V. Tran-Fadulu, C. L. Papke et al., "MYH11 mutations result in a distinct vascular pathology driven by insulin-like growth factor 1 and angiotensin II," Human Molecular Genetics, vol. 16, no. 20, pp. 2453-2462, 2007.

[16] L. Zhu, R. Vranckx, P. K. Van Kien et al., "Mutations in myosin heavy chain 11 cause a syndrome associating thoracic aortic aneurysm/aortic dissection and patent ductus arteriosus," Nature Genetics, vol. 38, no. 3, pp. 343-349, 2006.

[17] D.-C. Guo, H. Pannu, V. Tran-Fadulu et al., "Mutations in smooth muscle $\alpha$-actin (ACTA2) lead to thoracic aortic aneurysms and dissections," Nature Genetics, vol. 39, no. 12, pp. 1488-1493, 2007.

[18] D.-C. Guo, C. L. Papke, V. Tran-Fadulu et al., "Mutations in smooth muscle alpha-actin (ACTA2) cause coronary artery disease, stroke, and Moyamoya disease, along with thoracic aortic disease," The American Journal of Human Genetics, vol. 84, no. 5, pp. 617-627, 2009.

[19] D.-C. Guo, E. S. Regalado, L. Gong et al., "LOX mutations predispose to thoracic aortic aneurysms and dissections," Circulation Research, vol. 118, no. 6, pp. 928-934, 2016.

[20] D.-C. Guo, L. Gong, E. S. Regalado et al., "MAT2A mutations predispose individuals to thoracic aortic aneurysms," American Journal of Human Genetics, vol. 96, no. 1, pp. 170-177, 2015.

[21] E. S. Regalado, D.-C. Guo, C. Villamizar et al., "Exome sequencing identifies SMAD3 mutations as a cause of familial thoracic aortic aneurysm and dissection with intracranial and other arterial aneurysms," Circulation Research, vol. 109, no. 6, pp. 680-686, 2011.

[22] I. M. B. H. Van De Laar, R. A. Oldenburg, G. Pals et al., "Mutations in SMAD3 cause a syndromic form of aortic aneurysms and dissections with early-onset osteoarthritis," Nature Genetics, vol. 43, no. 2, pp. 121-126, 2011.

[23] I. S. Lantinga-van Leeuwen, J. G. Dauwerse, H. J. Baelde et al., "Lowering of Pkd1 expression is sufficient to cause polycystic kidney disease," Human Molecular Genetics, vol. 13, no. 24, pp. 3069-3077, 2004.

[24] R. Torra, C. Nicolau, C. Badenas et al., "Abdominal aortic aneurysms and autosomal dominant polycystic kidney disease," Journal of the American Society of Nephrology, vol. 7, no. 11, pp. 2483-2486, 1996.

[25] J. M. Friedman, J. Arbiter, J. A. Epstein et al., "Cardiovascular disease in neurofibromatosis 1: report of the NF1 Cardiovascular Task Force," Genetics in Medicine, vol. 4, no. 3, pp. 105-111, 2002.

[26] B. K. Stansfield, W. K. Bessler, R. Mali et al., "Ras-mek-erk signaling regulates Nf1 heterozygous neointima formation," American Journal of Pathology, vol. 184, no. 1, pp. 79-85, 2014.

[27] F. Li, B. D. Downing, L. C. Smiley et al., "Neurofibromindeficient myeloid cells are critical mediators of aneurysm formation in vivo," Circulation, vol. 129, no. 11, pp. 1213-1224, 2014. 
[28] H. Yanagisawa, E. C. Davist, B. C. Starcher et al., "Fibulin-5 is an elastin-binding protein essential for elastic fibre development in vivo," Nature, vol. 415, no. 6868, pp. 168-171, 2002.

[29] M. Orriols, S. Varona, I. Martí-Pàmies et al., "Down-regulation of Fibulin-5 is associated with aortic dilation: role of inflammation and epigenetics," Cardiovascular Research, vol. 110, no. 3, pp. 431-442, 2016.

[30] S. A. Badger, C. V. Soong, M. E. O’Donnell, M. A. Sharif, R. R. Makar, and A. E. Hughes, "Common polymorphisms of Fibulin-5 and the risk of abdominal aortic aneurysm development," Vascular Medicine, vol. 15, no. 2, pp. 113-117, 2010.

[31] I. Hinterseher, H. Bergert, E. Kuhlisch et al., "Matrix metalloproteinase 2 polymorphisms in a caucasian population with abdominal aortic aneurysm," Journal of Surgical Research, vol. 133, no. 2, pp. 121-128, 2006.

[32] L. Smallwood, R. Allcock, F. Van Bockxmeer et al., "Polymorphisms of the matrix metalloproteinase 9 gene and abdominal aortic aneurysm," British Journal of Surgery, vol. 95, no. 10, pp. 1239-1244, 2008.

[33] G. M. Longo, S. J. Buda, N. Fiotta et al., "MMP-12 has a role in abdominal aortic aneurysms in mice," Surgery, vol. 137, no. 4, pp. 457-562, 2005.

[34] J. Deguara, K. G. Burnand, J. Berg et al., "An increased frequency of the 5A allele in the promoter region of the MMP3 gene is associated with abdominal aortic aneurysms," Human Molecular Genetics, vol. 16, no. 24, pp. 3002-3007, 2007.

[35] N. Lamblin, C. Bauters, X. Hermant, J.-M. Lablanche, N. Helbecque, and P. Amouyel, "Polymorphisms in the promoter regions of MMP-2, MMP-3, MMP-9 and MMP-12 genes as determinants of aneurysmal coronary artery disease," Journal of the American College of Cardiology, vol. 40, no. 1, pp. 43-48, 2002.

[36] M. J. Bown, G. T. Jones, S. C. Harrison et al., "Abdominal aortic aneurysm is associated with a variant in low-density lipoprotein receptor-related protein 1," The American Journal of Human Genetics, vol. 89, no. 5, pp. 619-627, 2011.

[37] D. T. Bradley, A. E. Hughes, S. A. Badger et al., "A variant in LDLR is associated with abdominal aortic aneurysm," Circulation: Cardiovascular Genetics, vol. 6, no. 5, pp. 498-504, 2013.

[38] L. U. Gerdes, J. S. Lindholt, S. Vammen, E. W. Henneberg, and H. Fasting, "Apolipoprotein E genotype is associated with differential expansion rates of small abdominal aortic aneurysms," British Journal of Surgery, vol. 87, no. 6, pp. 760-765, 2000.

[39] J. W. Cornwall, R. S. Green, J. C. Nielsen, and B. D. Gelb, "Frequency of aortic dilation in Noonan syndrome," The American Journal of Cardiology, vol. 113, no. 2, pp. 368-371, 2014.

[40] M. E. Lindsay and H. C. Dietz, "Lessons on the pathogenesis of aneurysm from heritable conditions," Nature, vol. 473, no. 7347, pp. 308-316, 2011.

[41] R. Purnell, I. Williams, U. Von Oppell, and A. Wood, "Giant aneurysms of the sinuses of Valsalva and aortic regurgitation in a patient with Noonan's syndrome," European Journal of CardioThoracic Surgery, vol. 28, no. 2, pp. 346-348, 2005.

[42] H. Cao, X. Hu, Q. Zhang et al., "Hyperhomocysteinaemia, low folate concentrations and MTHFR C677T mutation in abdominal aortic aneurysm," Vasa-European Journal of Vascular Medicine, vol. 43, no. 3, pp. 181-188, 2014.

[43] J. Liu, X. Jia, H. Li et al., "Association between MTHFR C677T polymorphism and abdominal aortic aneurysm risk," Medicine, vol. 95, no. 36, Article ID e4793, 2016.
[44] F. Ferrara, S. Novo, S. Grimaudo et al., "Methylenetetrahydrofolate reductase mutation in subjects with abdominal aortic aneurysm subdivided for age," Clinical Hemorheology and Microcirculation, vol. 34, no. 3, pp. 421-426, 2006.

[45] C. M. Bhamidipati, C. A. Whatling, G. S. Mehta et al., "5-Lipoxygenase pathway in experimental abdominal aortic aneurysms," Arteriosclerosis, Thrombosis, and Vascular Biology, vol. 34, no. 12, pp. 2669-2678, 2014.

[46] L. Zhao, M. P. W. Moos, R. Gräbner et al., "The 5-lipoxygenase pathway promotes pathogenesis of hyperlipidemia-dependent aortic aneurysm," Nature Medicine, vol. 10, no. 9, pp. 966-973, 2004.

[47] E. J. Ryer, K. E. Ronning, R. Erdman et al., "The potential role of DNA methylation in abdominal aortic aneurysms," International Journal of Molecular Sciences, vol. 16, no. 5, pp. 11259-11275, 2015.

[48] L. Maegdefessel, J. Azuma, R. Toh et al., "MicroRNA-21 blocks abdominal aortic aneurysm development and nicotineaugmented expansion," Science Translational Medicine, vol. 4, no. 122, Article ID 122ra22, 2012.

[49] L. Maegdefessel, J. Azuma, R. Toh et al., "Inhibition of microRNA-29b reduces murine abdominal aortic aneurysm development," The Journal of Clinical Investigation, vol. 122, no. 2, pp. 497-506, 2012.

[50] D. R. Merk, J. T. Chin, B. A. Dake et al., "miR-29b participates in early aneurysm development in Marfan syndrome," Circulation Research, vol. 110, no. 2, pp. 312-324, 2012.

[51] S. S. Chaudhry, S. A. Cain, A. Morgan, S. L. Dallas, C. A. Shuttleworth, and C. M. Kielty, "Fibrillin-1 regulates the bioavailability of TGF $\beta 1$," The Journal of Cell Biology, vol. 176, no. 3, pp. 355-367, 2007.

[52] F. Ramirez, L. Y. Sakai, D. B. Rifkin, and H. C. Dietz, "Extracellular microfibrils in development and disease," Cellular and Molecular Life Sciences, vol. 64, no. 18, pp. 2437-2446, 2007.

[53] B. L. Loeys, U. Schwarze, T. Holm et al., "Aneurysm syndromes caused by mutations in the TGF- $\beta$ receptor," New England Journal of Medicine, vol. 355, no. 8, pp. 788-798, 2006.

[54] H. Pannu, V. Tran-Fadulu, and D. M. Milewicz, "Genetic basis of thoracic aortic aneurysms and aortic dissections," American Journal of Medical Genetics Part C: Seminars in Medical Genetics, vol. 139, no. 1, pp. 10-16, 2005.

[55] H. Pannu, V. T. Fadulu, J. Chang et al., "Mutations in transforming growth factor- $\beta$ receptor type II cause familial thoracic aortic aneurysms and dissections," Circulation, vol. 112, no. 4, pp. 513-520, 2005.

[56] D.-C. Guo, E. Regalado, D. E. Casteel et al., "Recurrent gain-offunction mutation in PRKG1 causes thoracic aortic aneurysms and acute aortic dissections," American Journal of Human Genetics, vol. 93, no. 2, pp. 398-404, 2013.

[57] D.-C. Guo, E. S. Regalado, C. Minn et al., "Familial thoracic aortic aneurysms and dissections identification of a novel locus for stable aneurysms with a low risk for progression to aortic dissection," Circulation: Cardiovascular Genetics, vol. 4, no. 1, pp. 36-42, 2011.

[58] S.-Q. Kuang, O. Medina-Martinez, D.-C. Guo et al., "FOXE3 mutations predispose to thoracic aortic aneurysms and dissections," The Journal of Clinical Investigation, vol. 126, no. 3, pp. 948-961, 2016.

[59] E. Regalado, S. Medrek, V. Tran-Fadulu et al., "Autosomal dominant inheritance of a predisposition to thoracic aortic aneurysms and dissections and intracranial saccular 
aneurysms," American Journal of Medical Genetics A, vol. 155, no. 9, pp. 2125-2130, 2011.

[60] D. M. Milewicz and E. Regalado, "Thoracic aortic aneurysms and aortic dissections," in GeneReviews ${ }^{\circledR}$, R. A. Pagon, M. P. Adam, H. H. Ardinger et al., Eds., University of Washington, Seattle, Wash, USA, 1993.

[61] D. M. Milewicz and E. S. Regalado, "Use of genetics for personalized management of heritable thoracic aortic disease: how do we get there?" The Journal of Thoracic and Cardiovascular Surgery, vol. 149, no. 2, pp. S3-S5, 2015.

[62] A. B. Chapman, D. Rubinstein, R. Hughes et al., "Intracranial aneurysms in autosomal dominant polycystic kidney disease," The New England Journal of Medicine, vol. 327, no. 13, pp. 916920, 1992.

[63] T. Ecder and R. W. Schrier, "Cardiovascular abnormalities in autosomal-dominant polycystic kidney disease," Nature Reviews Nephrology, vol. 5, no. 4, pp. 221-228, 2009.

[64] S. Hassane, N. Claij, I. S. Lantinga-van Leeuwen et al., "Pathogenic sequence for dissecting aneurysm formation in a hypomorphic polycystic kidney disease 1 mouse model," Arteriosclerosis, Thrombosis, and Vascular Biology, vol. 27, no. 10, pp. 2177-2183, 2007.

[65] I. Hinterseher, G. Tromp, and H. Kuivaniemi, "Genes and abdominal aortic aneurysm," Annals of Vascular Surgery, vol. 25, no. 3, pp. 388-412, 2011.

[66] A. F. Baas, J. Medic, R. van't Slot et al., "Association study of single nucleotide polymorphisms on chromosome 19q13 with abdominal aortic aneurysm," Angiology, vol. 61, no. 3, pp. 243247, 2010.

[67] J. R. Elmore, M. A. Obmann, H. Kuivaniemi et al., "Identification of a genetic variant associated with abdominal aortic aneurysms on chromosome 3 p12.3 by genome wide association," Journal of Vascular Surgery, vol. 49, no. 6, pp. 1525-1531, 2009.

[68] S. Gretarsdottir, A. F. Baas, G. Thorleifsson et al., "Genomewide association study identifies a sequence variant within the DAB2IP gene conferring susceptibility to abdominal aortic aneurysm," Nature Genetics, vol. 42, no. 8, pp. 692-697, 2010.

[69] L. Faivre, G. Collod-Beroud, B. Callewaert et al., "Pathogenic FBN1 mutations in 146 adults not meeting clinical diagnostic criteria for marfan syndrome: further delineation of type 1 fibrillinopathies and focus on patients with an isolated major criterion," American Journal of Medical Genetics, Part A, vol. 149, no. 5, pp. 854-860, 2009.

[70] B. Loeys, L. Van Maldergem, G. Mortier et al., "Homozygosity for a missense mutation in fibulin-5 (FBLN5) results in a severe form of cutis laxa," Human Molecular Genetics, vol. 11, no. 18, pp. 2113-2118, 2002.

[71] C. L. Papke and H. Yanagisawa, "Fibulin-4 and fibulin-5 in elastogenesis and beyond: insights from mouse and human studies," Matrix Biology, vol. 37, pp. 142-149, 2014.

[72] A. K. Ewart, C. A. Morris, D. Atkinson et al., "Hemizygosity at the elastin locus in a developmental disorder, Williams syndrome," Nature Genetics, vol. 5, no. 1, pp. 11-16, 1993.

[73] J. E. Wagenseil, C. H. Ciliberto, R. H. Knutsen, M. A. Levy, A. Kovacs, and R. P. Mecham, "The importance of elastin to aortic development in mice," American Journal of PhysiologyHeart and Circulatory Physiology, vol. 299, no. 2, pp. H257H264, 2010.

[74] W.-H. Fan and M. J. Karnovsky, "Increased MMP-2 expression in connective tissue growth factor over-expression vascular smooth muscle cells," The Journal of Biological Chemistry, vol. 277, no. 12, pp. 9800-9805, 2002.

[75] G. M. Longo, W. Xiong, T. C. Greiner, Y. Zhao, N. Fiotti, and B. T. Baxter, "Matrix metalloproteinases 2 and 9 work in concert to produce aortic aneurysms," The Journal of Clinical Investigation, vol. 110, no. 5, pp. 625-632, 2002.

[76] J. S. Matsumura and W. H. Pearce, "Infrarenal aortic aneurysms," The New England Journal of Medicine, vol. 336, no. 24, pp. 1756-1758, 1997.

[77] N. Sakalihasan, P. Delvenne, B. V. Nusgens, R. Limet, and C. M. Lapiere, "Activated forms of MMP2 and MMP9 in abdominal aortic aneurysms," Journal of Vascular Surgery, vol. 24, no. 1, pp. 127-133, 1996.

[78] U. Schönbeck, F. Mach, G. K. Sukhova et al., "Regulation of matrix metalloproteinase expression in human vascular smooth muscle cells by T lymphocytes: a role for CD40 signaling in plaque rupture?" Circulation Research, vol. 81, no. 3, pp. 448454, 1997.

[79] N. A. Tamarina, W. D. McMillan, V. P. Shively, and W. H. Pearce, "Expression of matrix metalloproteinases and their inhibitors in aneurysms and normal aorta," Surgery, vol. 122, no. 2, pp. 264272, 1997.

[80] M. Folkesson, M. Kazi, C. Zhu et al., "Presence of NGAL/MMP9 complexes in human abdominal aortic aneurysms," Thrombosis and Haemostasis, vol. 98, no. 2, pp. 427-433, 2007.

[81] A. R. Thompson, F. Drenos, H. Hafez, and S. E. Humphries, "Candidate gene association studies in abdominal aortic aneurysm disease: a review and meta-analysis," European Journal of Vascular and Endovascular Surgery, vol. 35, no. 1, pp. 1930, 2008.

[82] E. R. Neptune, P. A. Frischmeyer, D. E. Arking et al., "Dysregulation of TGF- $\beta$ activation contributes to pathogenesis in Marfan syndrome," Nature Genetics, vol. 33, no. 3, pp. 407-411, 2003.

[83] E. Gillis, L. Van Laer, and B. L. Loeys, "Genetics of thoracic aortic aneurysm: at the crossroad of transforming growth factor$\beta$ signaling and vascular smooth muscle cell contractility," Circulation Research, vol. 113, no. 3, pp. 327-340, 2013.

[84] J. P. Habashi, D. P. Judge, T. M. Holm et al., "Losartan, an AT1 antagonist, prevents aortic aneurysm in a mouse model of Marfan syndrome," Science, vol. 312, no. 5770, pp. 117-121, 2006.

[85] J. P. Habashi, J. J. Doyle, T. M. Holm et al., "Angiotensin II type 2 receptor signaling attenuates aortic aneurysm in mice through ERK antagonism," Science, vol. 332, no. 6027, pp. 361-365, 2011.

[86] T. M. Holm, J. P. Habashi, J. J. Doyle et al., "Noncanonical TGF $\beta$ signaling contributes to aortic aneurysm progression in marfan syndrome mice," Science, vol. 332, no. 6027, pp. 358-361, 2011.

[87] Y. Wang, S. Krishna, P. J. Walker, P. Norman, and J. Golledge, "Transforming growth factor- $\beta$ and abdominal aortic aneurysms," Cardiovascular Pathology, vol. 22, no. 2, pp. 126132, 2013.

[88] Y. Wang, H. Ait-Oufella, O. Herbin et al., "TGF- $\beta$ activity protects against inflammatory aortic aneurysm progression and complications in angiotensin II-infused mice," The Journal of Clinical Investigation, vol. 120, no. 2, pp. 422-432, 2010.

[89] F. Gao, P. Chambon, S. Offermanns et al., "Disruption of TGF- $\beta$ signaling in smooth muscle cell prevents elastaseinduced abdominal aortic aneurysm," Biochemical and Biophysical Research Communications, vol. 454, no. 1, pp. 137-143, 2014.

[90] H. Ait-Oufella, Y. Wang, O. Herbin, A. Tedgui, and Z. Mallat, "Role of TGF $\beta$ in a model of abdominal aortic aneurysm in mice," Médecine Science, vol. 26, no. 10, pp. 795-797, 2010. 
[91] L. Lucarini, E. Sticchi, F. Sofi et al., "ACE and TGFBR1 genes interact in influencing the susceptibility to abdominal aortic aneurysm," Atherosclerosis, vol. 202, no. 1, pp. 205-210, 2009.

[92] A. Siegert, E. Ritz, S. Orth, and J. Wagner, "Differential regulation of transforming growth factor receptors by angiotensin II and transforming growth factor- $\beta 1$ in vascular smooth muscle," Journal of Molecular Medicine, vol. 77, no. 5, pp. 437-445, 1999.

[93] N. Fukuda, W.-Y. Hu, A. Kubo et al., "Angiotensin II upregulates transforming growth factor- $\beta$ type I receptor on rat vascular smooth muscle cells," American Journal of Hypertension, vol. 13, no. 2, pp. 191-198, 2000.

[94] L. Zhu, D. Bonnet, M. Boussion, B. Vedie, D. Sidi, and X. Jeunemaitre, "Investigation of the MYH11 gene in sporadic patients with an isolated persistently patent arterial duct," Cardiology in the Young, vol. 17, no. 6, pp. 666-672, 2007.

[95] A. K. Soutar and R. P. Naoumova, "Mechanisms of disease: genetic causes of familial hypercholesterolemia," Nature Clinical Practice Cardiovascular Medicine, vol. 4, no. 4, pp. 214-225, 2007.

[96] M. J. Bown, "Genomic insights into abdominal aortic aneurysms," Annals of the Royal College of Surgeons of England, vol. 96, no. 6, pp. 405-414, 2014.

[97] D. C. Ewbank, "The APOE gene and differences in life expectancy in Europe," The Journals of Gerontology-Series A Biological Sciences and Medical Sciences, vol. 59, no. 1, pp. 1620, 2004.

[98] L. U. Gerdes, B. Jeune, K. A. Ranberg, H. Nybo, and J. W. Vaupel, "Estimation of apolipoprotein E genotype-specific relative mortality risks from the distribution of genotypes in centenarians and middle-aged men: apolipoprotein $\mathrm{E}$ gene is a 'frailty gene,' not a 'longevity gene,' Genetic Epidemiology, vol. 19, no. 3, pp. 202-210, 2000.

[99] R. Jacobsen, T. Martinussen, L. Christiansen et al., "Increased effect of the ApoE gene on survival at advanced age in healthy and long-lived Danes: two nationwide cohort studies," Aging Cell, vol. 9, no. 6, pp. 1004-1009, 2010.

[100] D. Viskochil, A. M. Buchberg, G. Xu et al., "Deletions and a translocation interrupt a cloned gene at the neurofibromatosis type 1 locus," Cell, vol. 62, no. 1, pp. 187-192, 1990.

[101] W. K. Bessler, F. Z. Hudson, H. Zhang et al., "Neurofibromin is a novel regulator of Ras-induced reactive oxygen species production in mice and humans," Free Radical Biology \& Medicine, vol. 97, pp. 212-222, 2016.

[102] W. K. Bessler, G. Kim, F. Z. Hudson et al., "Nf1 ${ }^{+/-}$monocytes/macrophages induce neointima formation via CCR2 activation," Human Molecular Genetics, vol. 25, no. 6, pp. 1129-1139, 2016.

[103] B. K. Stansfield, W. K. Bessler, R. Mali et al., "Heterozygous inactivation of the NF1 gene in myeloid cells enhances neointima formation via a rosuvastatin-sensitive cellular pathway," Human Molecular Genetics, vol. 22, no. 5, pp. 977-988, 2013.

[104] J. E. Allanson, M. Upadhyaya, G. H. Watson et al., "Watson syndrome: is it a subtype of type 1 neurofibromatosis?" Journal of Medical Genetics, vol. 28, no. 11, pp. 752-756, 1991.

[105] G. S. Oderich, T. M. Sullivan, T. C. Bower et al., "Vascular abnormalities in patients with neurofibromatosis syndrome type I: clinical spectrum, management, and results," Journal of Vascular Surgery, vol. 46, no. 3, pp. 475-484, 2007.

[106] D. Rea, J. F. Brandsema, D. Armstrong et al., "Cerebral arteriopathy in children with neurofibromatosis type 1," Pediatrics, vol. 124, no. 3, pp. e476-e483, 2009.
[107] E. Fossali, E. Signorini, R. C. Intermite et al., "Renovascular disease and hypertension in children with neurofibromatosis," Pediatric Nephrology, vol. 14, no. 8-9, pp. 806-810, 2000.

[108] M. Henkemeyer, D. J. Rossi, D. P. Holmyard et al., "Vascular system defects and neuronal apoptosis in mice lacking Ras GTPase-activating protein," Nature, vol. 377, no. 6551, pp. 695701, 1995.

[109] T. L. Rosser, G. Vezina, and R. J. Packer, "Cerebrovascular abnormalities in a population of children with neurofibromatosis type 1," Neurology, vol. 64, no. 3, pp. 553-555, 2005.

[110] S. A. Lemaire, X. Wang, J. A. Wilks et al., "Matrix metalloproteinases in ascending aortic aneurysms: bicuspid versus trileaflet aortic valves," Journal of Surgical Research, vol. 123, no. 1, pp. 40-48, 2005.

[111] W. D. McMillan, N. A. Tamarina, M. Cipollone, D. A. Johnson, M. A. Parker, and W. H. Pearce, "Size matters: the relationship between MMP-9 expression and aortic diameter," Circulation, vol. 96, no. 7, pp. 2228-2232, 1997.

[112] M. Shen, J. Lee, R. Basu et al., "Divergent roles of matrix metalloproteinase 2 in pathogenesis of thoracic aortic aneurysm," Arteriosclerosis, Thrombosis, and Vascular Biology, vol. 35, no. 4, pp. 888-898, 2015.

[113] S. Zhang, B. Zhong, M. Chen et al., "Epigenetic reprogramming reverses the malignant epigenotype of the MMP/TIMP axis genes in tumor cells," International Journal of Cancer, vol. 134, no. 7, pp. 1583-1594, 2014.

[114] P. Stenvinkel, M. Karimi, S. Johansson et al., "Impact of inflammation on epigenetic DNA methylation-a novel risk factor for cardiovascular disease?" Journal of Internal Medicine, vol. 261, no. 5, pp. 488-499, 2007.

[115] N. R. Fuggle, F. A. Howe, R. Allen, and N. Sofat, "New insights into the impact of neuro-inflammation in rheumatoid arthritis," Frontiers in Neuroscience, vol. 8, article 357, 2014.

[116] I. T. Pereira, E. A. S. Ramos, E. T. Costa et al., "Fibronectin affects transient MMP2 gene expression through DNA demethylation changes in non-invasive breast cancer cell lines," PLoS ONE, vol. 9, no. 9, Article ID e105806, 2014.

[117] M. Ailenberg and M. Silverman, "Trichostatin A-histone deacetylase inhibitor with clinical therapeutic potential-is also a selective and potent inhibitor of gelatinase A expression," Biochemical and Biophysical Research Communications, vol. 298, no. 1, pp. 110-115, 2002.

[118] C. Yuan, L. Zhang, Y. Gao, D. Peng, J. Liu, and Y. Cai, "DNA demethylation at the promoter region enhances the expression of MMP-9 in ectopic endometrial stromal cells of endometriosis," Chinese Journal of Cellular and Molecular Immunology, vol. 30, no. 12, pp. 1258-1261, 2014.

[119] S. Nozell, Z. Ma, C. Wilson, R. Shah, and E. N. Benveniste, "Class II major histocompatibility complex transactivator (CIITA) inhibits matrix metalloproteinase-9 gene expression," The Journal of Biological Chemistry, vol. 279, no. 37, pp. 3857738589, 2004.

[120] C. Yan, H. Wang, Y. Toh, and D. D. Boyd, "Repression of 92-kDa type IV collagenase expression by MTA1 is mediated through direct interactions with the promoter via a mechanism, which is both dependent on and independent of histone deacetylation," The Journal of Biological Chemistry, vol. 278, no. 4, pp. 23092316, 2003.

[121] M. Galán, S. Varona, M. Orriols et al., "Induction of histone deacetylases (HDACs) in human abdominal aortic aneurysm: therapeutic potential of HDAC inhibitors," Disease Models and Mechanisms, vol. 9, no. 5, pp. 541-552, 2016. 
[122] A. Vinh, T. A. Gaspari, H. B. Liu, L. F. Dousha, R. E. Widdop, and A. E. Dear, "A novel histone deacetylase inhibitor reduces abdominal aortic aneurysm formation in angiotensin II-infused apolipoprotein E-deficient mice," Journal of Vascular Research, vol. 45, no. 2, pp. 143-152, 2008.

[123] T. Brunelli, D. Prisco, S. Fedi et al., "High prevalence of mild hyperhomocysteinemia in patients with abdominal aortic aneurysm," Journal of Vascular Surgery, vol. 32, no. 3, pp. 531$536,2000$.

[124] J. Liu, S. W. Zuo, Y. Li et al., "Hyperhomocysteinaemia is an independent risk factor of abdominal aortic aneurysm in a Chinese Han population," Scientific Reports, vol. 6, Article ID 17966, 2016.

[125] K. J. Halazun, K. A. Bofkin, S. Asthana, C. Evans, M. Henderson, and J. I. Spark, "Hyperhomocysteinaemia is associated with the rate of abdominal aortic aneurysm expansion," European Journal of Vascular and Endovascular Surgery, vol. 33, no. 4, pp. 391-394, 2007.

[126] S. M. Krishna, A. Dear, J. M. Craig, P. E. Norman, and J. Golledge, "The potential role of homocysteine mediated DNA methylation and associated epigenetic changes in abdominal aortic aneurysm formation," Atherosclerosis, vol. 228, no. 2, pp. 295-305, 2013.

[127] B. J. Toghill, A. Saratzis, S. C. Harrison, A. R. Verissimo, E. B. Mallon, and M. J. Bown, "The potential role of DNA methylation in the pathogenesis of abdominal aortic aneurysm," Atherosclerosis, vol. 241, no. 1, pp. 121-129, 2015.

[128] Z. Chen, A. C. Karaplis, S. L. Ackerman et al., "Mice deficient in methylenetetrahydrofolate reductase exhibit hyperhomocysteinemia and decreased methylation capacity, with neuropathology and aortic lipid deposition," Human Molecular Genetics, vol. 10, no. 5, pp. 433-443, 2001.

[129] K. W. K. Lee and Z. Pausova, "Cigarette smoking and DNA methylation," Frontiers in Genetics, vol. 4, article no. 132, 2013.

[130] L. P. Breitling, R. Yang, B. Korn, B. Burwinkel, and H. Brenner, "Tobacco-smoking-related differential DNA methylation: $27 \mathrm{~K}$ discovery and replication," American Journal of Human Genetics, vol. 88, no. 4, pp. 450-457, 2011.

[131] B. A. Mercer, A. M. Wallace, C. E. Brinckerhoff, and J. M. D'Armiento, "Identification of a cigarette smoke-responsive region in the distal MMP-1 promoter," American Journal of Respiratory Cell and Molecular Biology, vol. 40, no. 1, pp. 4-12, 2009.

[132] R. Satta, E. Maloku, A. Zhubi et al., "Nicotine decreases DNA methyltransferase 1 expression and glutamic acid decarboxylase 67 promoter methylation in GABAergic interneurons," Proceedings of the National Academy of Sciences of the United States of America, vol. 105, no. 42, pp. 16356-16361, 2008.

[133] R. Joehanes, A. C. Just, R. E. Marioni et al., "Epigenetic signatures of cigarette smoking," Circulation: Cardiovascular Genetics, vol. 9, no. 5, pp. 436-447, 2016.

[134] L. G. Tsaprouni, T.-P. Yang, J. Bell et al., "Cigarette smoking reduces DNA methylation levels at multiple genomic loci but the effect is partially reversible upon cessation," Epigenetics, vol. 9, no. 10, pp. 1382-1396, 2014.

[135] S. Ambatipudi, C. Cuenin, H. Hernandez-Vargas et al., "Tobacco smoking-associated genome-wide DNA methylation changes in the EPIC study," Epigenomics, vol. 8, no. 5, pp. 599618, 2016.

[136] M. M. Monick, S. R. H. Beach, J. Plume et al., "Coordinated changes in AHRR methylation in lymphoblasts and pulmonary macrophages from smokers," American Journal of Medical Genetics, Part B: Neuropsychiatric Genetics, vol. 159, no. 2, pp. 141-151, 2012.

[137] J. Sandoval, H. A. Heyn, S. Moran et al., "Validation of a DNA methylation microarray for $450,000 \mathrm{CpG}$ sites in the human genome," Epigenetics, vol. 6, no. 6, pp. 692-702, 2011.

[138] U. P. Kelavkar, N. S. Harya, J. Hutzley et al., "DNA methylation paradigm shift: 15-lipoxygenase-1 upregulation in prostatic intraepithelial neoplasia and prostate cancer by atypical promoter hypermethylation," Prostaglandins and Other Lipid Mediators, vol. 82, no. 1-4, pp. 185-197, 2007.

[139] H. Takagi and T. Umemoto, "Smoking promotes pathogenesis of aortic aneurysm through the 5-lipoxygenase pathway," Medical Hypotheses, vol. 64, no. 6, pp. 1117-1119, 2005.

[140] P. A. Jones, S. M. Taylor, and V. L. Wilson, "Inhibition of DNA methylation by 5-azacytidine," Recent Results in Cancer Research, vol. 84, pp. 202-211, 1983.

[141] V. L. Wilson and P. A. Jones, "DNA methylation decreases in aging but not in immortal cells," Science, vol. 220, no. 4601, pp. 1055-1057, 1983.

[142] M. Jung and G. P. Pfeifer, "Aging and DNA methylation," BMC Biology, vol. 13, article 7, 2015.

[143] M. O. Hiltunen, M. P. Turunen, T. P. Häkkinen et al., "DNA hypomethylation and methyltransferase expression in atherosclerotic lesions," Vascular Medicine, vol. 7, no. 1, pp. 511, 2002.

[144] X. Lin, W. Zhang, Q. Lu et al., "Effect of MTHFR gene polymorphism impact on atherosclerosis via genome-wide methylation," Medical Science Monitor, vol. 22, pp. 341-345, 2016.

[145] S. B. Baylin, J. G. Herman, J. R. Graff, P. M. Vertino, and J. P. Issa, "Alterations in DNA methylation: a fundamental aspect of neoplasia," Advances in Cancer Research, vol. 72, pp. 141-169, 1998.

[146] M. El-Sammak, M. Kandil, S. El-Hifni, R. Hosni, and M. Ragab, "Elevated plasma homocysteine is positively associated with age independent of C677T mutation of the methylenetetrahydrofolate reductase gene in selected Egyptian subjects," International Journal of Medical Sciences, vol. 1, no. 3, pp. 181-192, 2004.

[147] L. D. Spotila, P. F. Jacques, P. B. Berger, K. V. Ballman, R. C. Ellison, and R. Rozen, "Age Dependence of the Influence of Methylenetetrahydrofolate Reductase Genotype on Plasma Homocysteine Level," American Journal of Epidemiology, vol. 158, no. 9, pp. 871-877, 2003.

[148] A. Straßburg, C. Krems, P. M. Lührmann, B. Hartmann, and M. Neuhäuser-Berthold, "Effect of age on plasma homocysteine concentrations in young and elderly subjects considering serum vitamin concentrations and different lifestyle factors," International Journal for Vitamin and Nutrition Research, vol. 74, no. 2, pp. 129-136, 2004.

[149] S. Horvath, "DNA methylation age of human tissues and cell types," Genome Biology, vol. 14, no. 10, article R115, 2013.

[150] S. Kochanek, A. Radbruch, H. Tesch, D. Renz, and W. Doerfler, "DNA methylation profiles in the human genes for tumor necrosis factors $\alpha$ and $\beta$ in subpopulations of leukocytes and in leukemias," Proceedings of the National Academy of Sciences of the United States of America, vol. 88, no. 13, pp. 5759-5763, 1991.

[151] Z. H. Liu, L. L. Chen, X. L. Deng et al., "Methylation status of $\mathrm{CpG}$ sites in the MCP-1 promoter is correlated to serum MCP-1 in type 2 diabetes," Journal of Endocrinological Investigation, vol. 35, no. 6, pp. 585-589, 2012. 
[152] K. E. Sullivan, A. B. M. Reddy, K. Dietzmann et al., "Epigenetic regulation of tumor necrosis factor alpha," Molecular and Cellular Biology, vol. 27, no. 14, pp. 5147-5160, 2007.

[153] J. Wang, Y. Jiang, A. Yang et al., "Hyperhomocysteinemiainduced monocyte chemoattractant protein-1 promoter DNA methylation by nuclear factor- $\kappa \mathrm{B} / \mathrm{DNA}$ methyltransferase 1 in apolipoprotein E-deficient mice," BioResearch Open Access, vol. 2, no. 2, pp. 118-127, 2013.

[154] I. Wessels, D. Fleischer, L. Rink, and P. Uciechowski, "Changes in chromatin structure and methylation of the human interleukin- $1 \beta$ gene during monopoiesis," Immunology, vol. 130, no. 3, pp. 410-417, 2010.

[155] J. Makino, R. Ogasawara, T. Kamiya et al., "Royal Jelly constituents increase the expression of extracellular superoxide dismutase through histone acetylation in monocytic THP-1 cells," Journal of Natural Products, vol. 79, no. 4, pp. 1137-1143, 2016.

[156] N. N. Soe, M. Sowden, P. Baskaran et al., "Acetylation of cyclophilin $\mathrm{A}$ is required for its secretion and vascular cell activation," Cardiovascular Research, vol. 101, no. 3, pp. 444-453, 2014.

[157] F. M. Moodie, J. A. Marwick, C. S. Anderson et al., "Oxidative stress and cigarette smoke alter chromatin remodeling but differentially regulate NF- $\kappa \mathrm{B}$ activation and proinflammatory cytokine release in alveolar epithelial cells," The FASEB Journal, vol. 18, no. 15, pp. 1897-1899, 2004.

[158] D. Pons, F. R. de Vries, P. J. van den Elsen, B. T. Heijmans, P. H. A. Quax, and J. W. Jukema, "Epigenetic histone acetylation modifiers in vascular remodelling: new targets for therapy in cardiovascular disease," European Heart Journal, vol. 30, no. 3, pp. 266-277, 2009.

[159] I. Hinterseher, R. Erdman, J. R. Elmore et al., "Novel pathways in the pathobiology of human abdominal aortic aneurysms," Pathobiology, vol. 80, no. 1, pp. 1-10, 2013.

[160] M. C. Pahl, K. Derr, G. Gäbel et al., "MicroRNA expression signature in human abdominal aortic aneurysms," BMC Medical Genomics, vol. 5, article 25, 2012.

[161] K. Kin, S. Miyagawa, S. Fukushima et al., "Tissue- and plasmaspecific MicroRNA signatures for atherosclerotic abdominal aortic aneurysm," Journal of the American Heart Association, vol. 1, no. 5, Article ID e000745, 2012.

[162] S.-G. Sun, B. Zheng, M. Han et al., "MiR-146a and Krüppel-like factor 4 form a feedback loop to participate in vascular smooth muscle cell proliferation," EMBO Reports, vol. 12, no. 1, pp. 5662, 2011.

[163] M. Adam, U. Raaz, J. M. Spin, and P. S. Tsao, "MicroRNAs in abdominal aortic aneurysm," Current Vascular Pharmacology, vol. 13, no. 3, pp. 280-290, 2015.

[164] W. Zhang, T. Shang, C. Huang et al., "Plasma microRNAs serve as potential biomarkers for abdominal aortic aneurysm," Clinical Biochemistry, vol. 48, no. 15, pp. 988-992, 2015.

[165] P. W. Stather, N. Sylvius, D. A. Sidloff et al., "Identification of microRNAs associated with abdominal aortic aneurysms and peripheral arterial disease," British Journal of Surgery, vol. 102, no. 7, pp. 755-766, 2015.

[166] R. A. Boon, T. Seeger, S. Heydt et al., "MicroRNA-29 in aortic dilation: implications for aneurysm formation," Circulation Research, vol. 109, no. 10, pp. 1115-1119, 2011.

[167] L. Maegdefessel, J. M. Spin, U. Raaz et al., "miR-24 limits aortic vascular inflammation and murine abdominal aneurysm development," Nature Communications, vol. 5, p. 5214, 2014.
[168] C. W. Kim, S. Kumar, D. J. Son, I.-H. Jang, K. K. Griendling, and H. Jo, "Prevention of abdominal aortic aneurysm by anti-microRNA-712 or anti-microRNA-205 in angiotensin IIinfused mice," Arteriosclerosis, Thrombosis, and Vascular Biology, vol. 34, no. 7, pp. 1412-1421, 2014. 


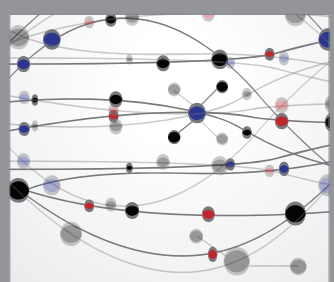

The Scientific World Journal
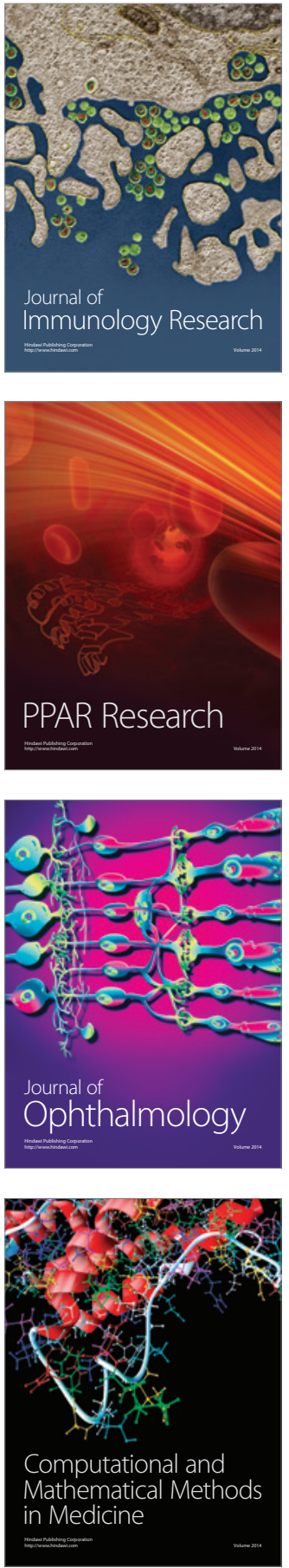

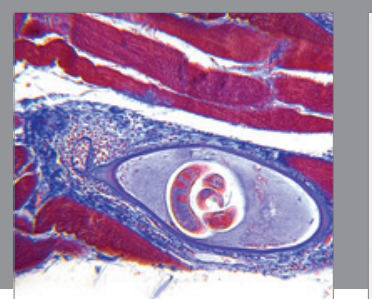

Gastroenterology Research and Practice
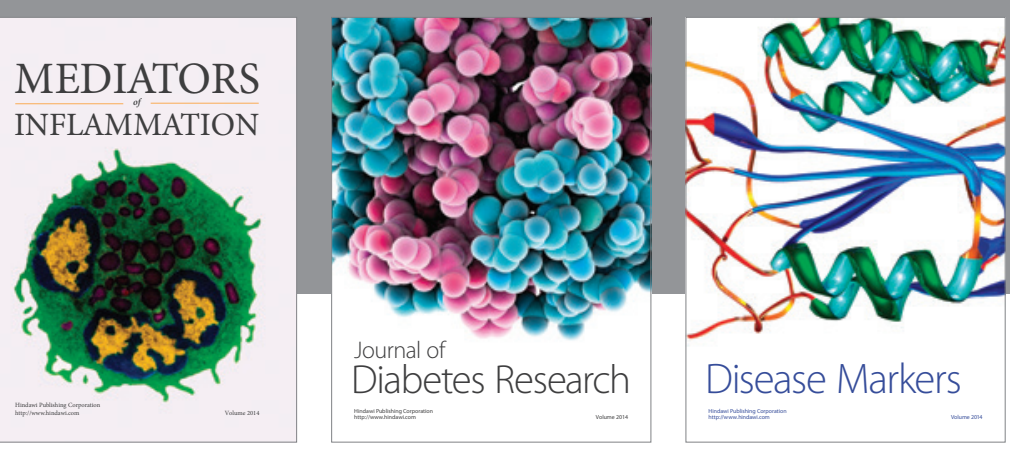

Disease Markers

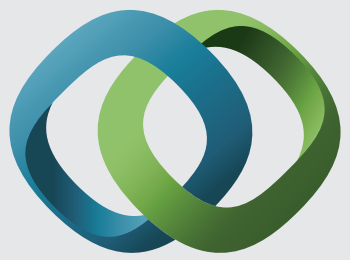

\section{Hindawi}

Submit your manuscripts at

https://www.hindawi.com
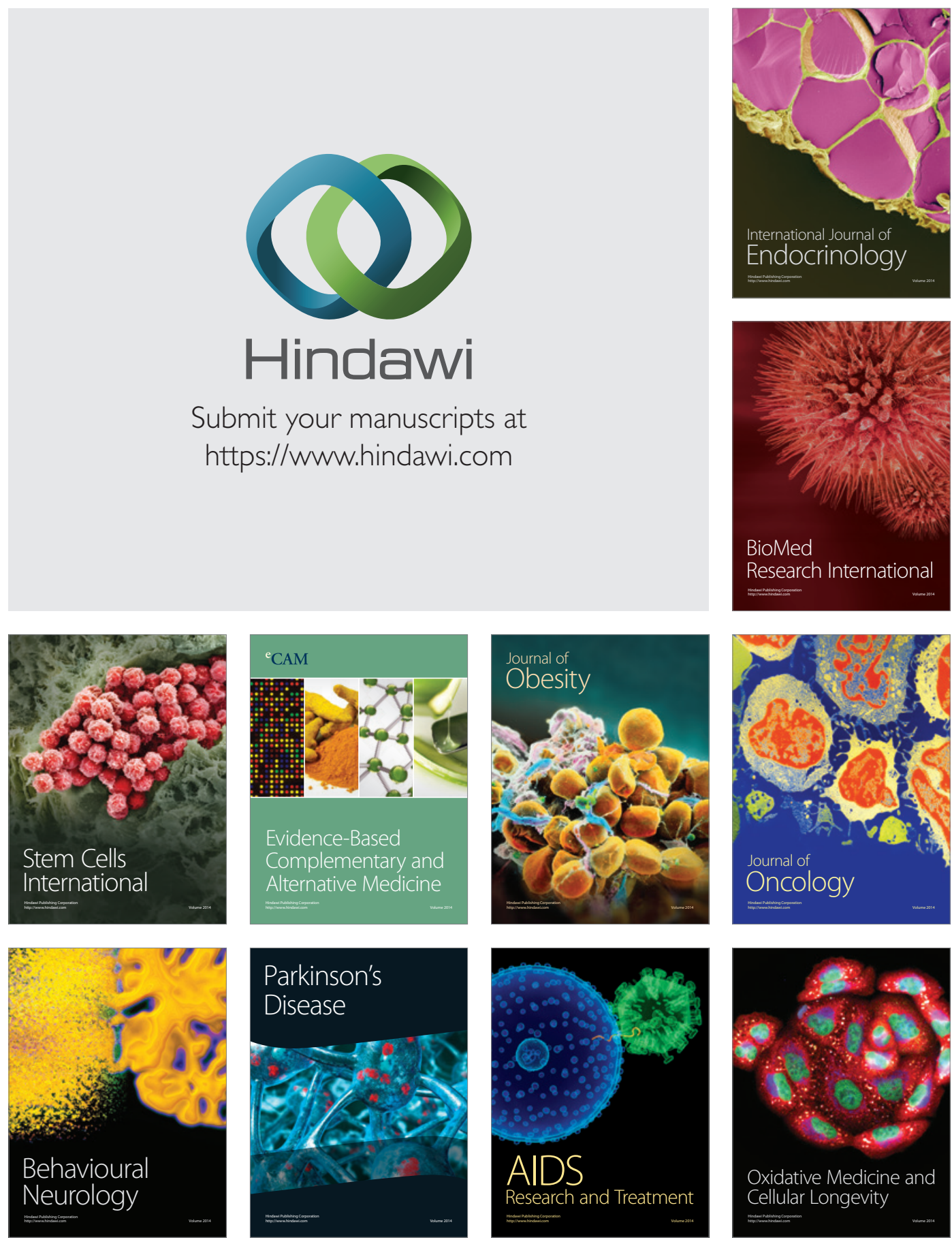